\title{
A Self-Diplexing Antenna Designed using SIW Technique for C-Band Applications
}

\author{
P.V. K Durga Prasad ${ }^{1}$, B. Kalyani ${ }^{2}$, P. Dharma Rao ${ }^{3}$, S K Fazeelath ${ }^{4}$, S K Aarif ${ }^{5}$ \\ ${ }^{12345}$ Depatment of Electronics and Communication Engineering \\ Raghu Institute of Technology, Visakhapatnam
}

\begin{abstract}
The paper explain how the substrate integrated waveguide can often used to implement a self-diplexing antenna for C-Band applications. The designed antenna exploits two quarter-mode SIW cavity resonators. Quartermode SIW cavity resonator is attained from the half-mode SIW cavity resonator by dividing with the assistance of 1 open ended slot. Each quarter-mode SIW cavity resonator is excited separately using microstrip feedlines. The antenna display two resonant frequencies of 6.44 and $7.09 \mathrm{GHz}$, with the subsequent gain values 4.8 and $6.2 \mathrm{~dB}$ respectively. Moreover, the antenna shows unidirectional and stable radiation diagram operating frequencies. The obtained frequencies are ranging between $4-8 \mathrm{GHz}$ so the designed antenna can be used for $\mathrm{C}$-Band applications.
\end{abstract}

Keywords:- Substrate integrated waveguide (SIW), Selfdiplexing antenna, quarter-mode SIW (QMSIW).

\section{INTRODUCTION:}

Nowadays wireless communication systems leading a serious role in communication, especially the software defined radios demand a compact, light weight, high performance dual band or multi band antennas [1-2]. SIW technology already experienced a rapid development over quite one decade. This development allows demonstration and applications of innovative passive and active circuits, antennas and systems at microwave and millimeter wave frequencies [3-5].

Some multilayered structures are wont to improve the isolation between the input ports [4-5]. In [6] and [7] using non-planar configuration the antennas with self-diplexing capability are implemented. Substrate integrated waveguide is implemented to beat the drawbacks of microstrip and DFW (dielectric filled waveguide). Dual Tstubs loaded apertures are developed in [8] using selfdiplexing antennas. SIW techniques are often utilized in many antenna designs to urge high performance at very high frequencies. SIW technique can be combined with other SIC's platforms to create multiformat and multifunction devices and systems. Using SIW cavitybacked self-diplexing antennas are demonstrated [9-10].

\subsection{HMSIW and QMSIW:}

It occupies large space because of the full wave SIW antenna. A big miniaturization of the SIW antenna is achieved by applying the SIW (HMSIW) and SIW quarter mode (QMSIW) half-wave mode [11-12].

The HMSIW has almost the equivalent distribution of the E-field as the full SIW, although its size is half that. QMSIW is attained by dividing the HMSIW into two parts.

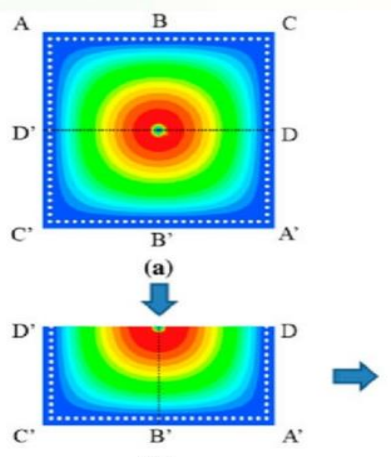

(b)

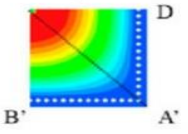

(c)
FIGURE 1: HMSIW and QMSIW

\section{DESIGN AND ANALYSIS}

2.1DESIGN: The specification proposed is prototyped using the copper laminated RT / Duroid 5880. Substratum $1.57 \mathrm{~mm}$ thick, dielectric constant 2.2 and loss tangent 0.0009 .

In this proposed design, HMSIW resonator operating in dominant mode is split into two unequal parts by etching a 1 open ended slanted rectangular slot. This slot transforms HMSIW into two unequal quarter-modes like cavity resonators.

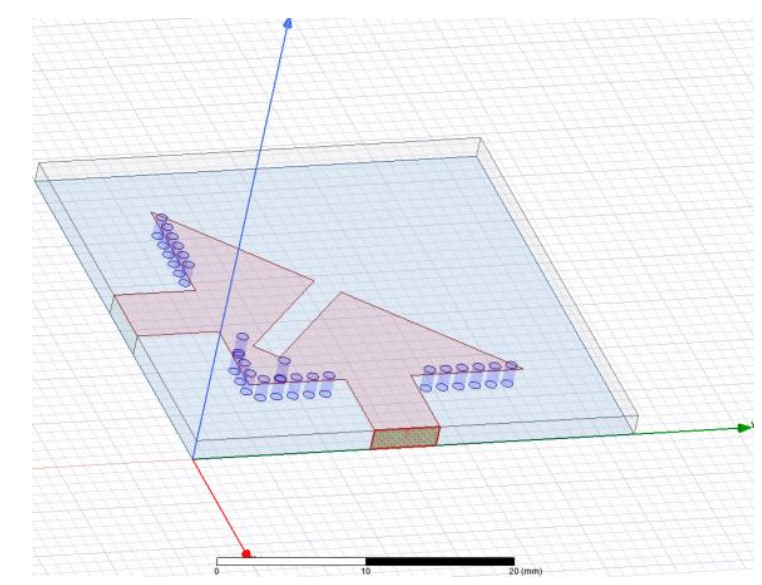

FIGURE 2: Design of self-diplexing antenna using SIW technique in HFSS

The required dimensions for the planning of this antenna are given below with schematic configuration of antenna 


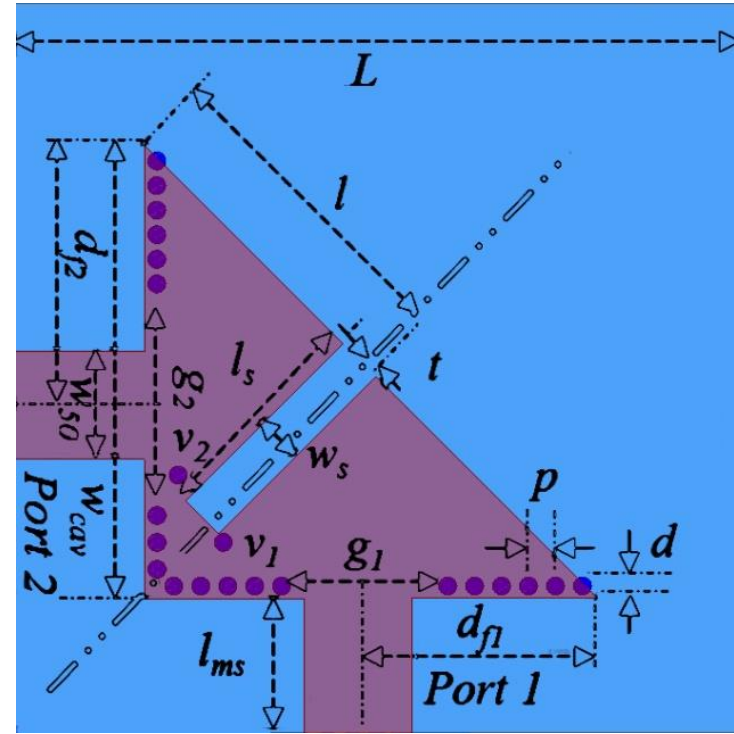

FIGURE 3: Schematic of antenna configuration

Table 1: Dimensions of antenna configuration

\begin{tabular}{|c|c|}
\hline Parameters & values \\
\hline $\mathrm{L}$ & 32.5 \\
\hline$w_{\text {cav }}$ & 20.2 \\
\hline$l_{s}$ & 9.9 \\
\hline$g_{1}$ & 7.1 \\
\hline$d_{f 1}$ & 10.7 \\
\hline$w_{50}$ & 4.1 \\
\hline$g_{2}$ & 8.2 \\
\hline$l_{m s}$ & 6.0 \\
\hline$l$ & 14.5 \\
\hline$w_{s}$ & 2.0 \\
\hline$d_{f 2}$ & 11.58 \\
\hline $\mathrm{H}$ & 1.57 \\
\hline $\mathrm{P}$ & 1.2 \\
\hline $\mathrm{D}$ & 0.8 \\
\hline
\end{tabular}

\subsection{ANALYSIS:}

\section{Port 1 only excited}

When the planning is completed the supported measuring configurations, it's simulated using Ansoft HFSS simulator by exciting only port 1 by microstrip line feeding at a frequency of $6.44 \mathrm{GHz}$ and port 2 is terminated employing a terminator, the maximum gain obtained is $4.8 \mathrm{~dB}$.

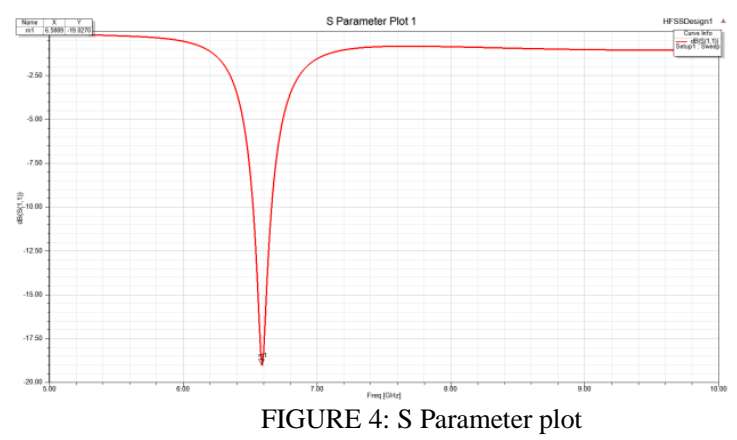

The above figure represents that when port 1 only excited the $\mathrm{S}$ Parameter value is $-19.0270 \mathrm{~dB}$ at frequency $6.5889 \mathrm{GHz}$.

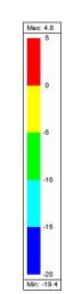

Gain Plot 1

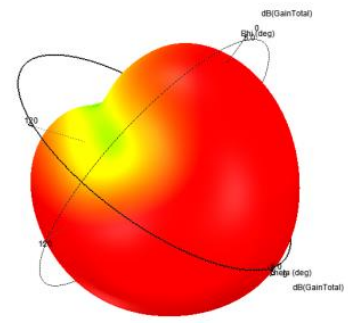

FIGURE 5: 3D Gain plot

The above figure represents that 3D Gain plot where it ranges from -19.4 to $4.8 \mathrm{~dB}$.

\section{Port 2 only excited}

When port 2 only excited by microstrip line feeding at a frequency $7.09 \mathrm{GHz}$ and terminating the port 1 . The utmost gain obtained is $6.2 \mathrm{~dB}$.

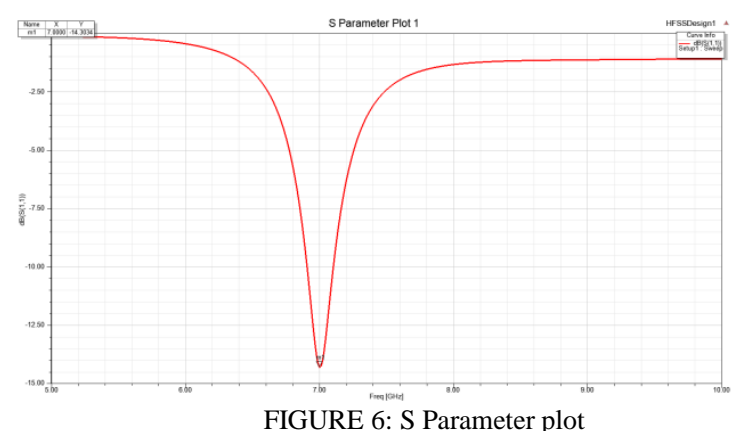

The above figure represents that when port 2 only excited the $\mathrm{S}$ Parameter value is $-14.3034 \mathrm{~dB}$ at frequency 7.00GHz.
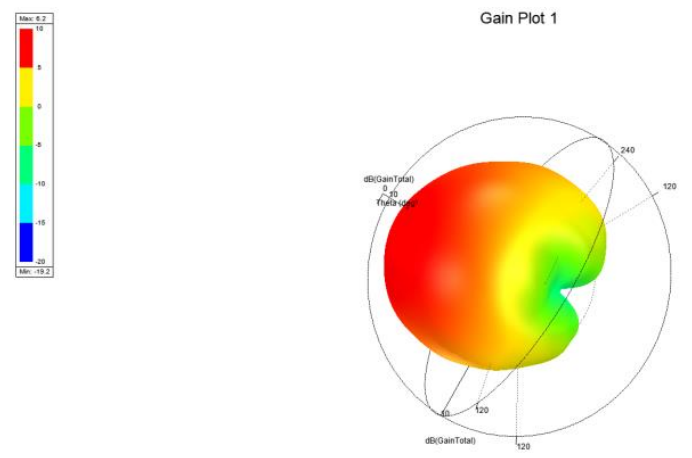

FIGURE7: 3D Gain plot

The above figure represents that 3D Gain plot where it ranges from -19.2 to $6.2 \mathrm{~dB}$.

\section{BOTH PORT 1 AND PORT 2 ARE EXCITED}

When port 1 and port 2 are excited at a time with two different operating frequencies i.e. 6.44 and $7.09 \mathrm{GHz}$. This exhibits the nature of Self-diplexing antenna as it is working at two different frequencies. 


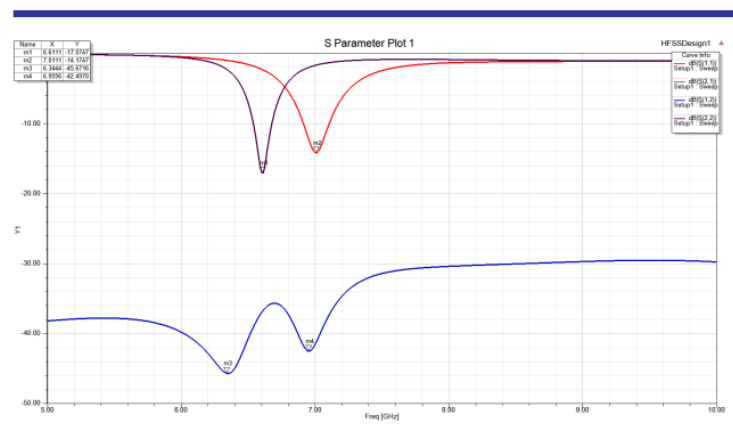

FIGURE 8: S Parameters plot

When both port 1 and port 2 are exited at simultaneously there exist four $S$ Parameters present. Those are $S(1,1)$ is $7.0111 \mathrm{~dB}$ at frequency $-14.17 \mathrm{GHz}, \mathrm{S}(1,2)$ has two values $-45.67 \mathrm{~dB},-45.49 \mathrm{~dB}$ at frequencies $6.34 \mathrm{GHz}, 6.95 \mathrm{GHz}$ and $\mathrm{S}(2,2)$ is $-17.07 \mathrm{~dB}$ at frequency $6.611 \mathrm{GHz}$.
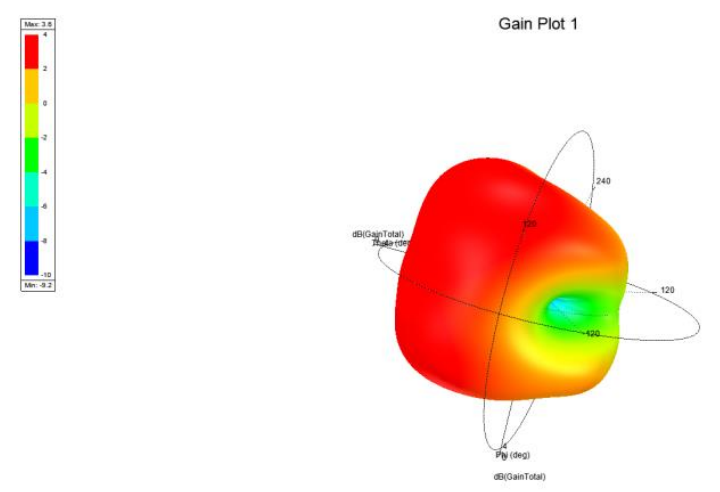

FIGURE 9: 3D Gain plot

The above figure represents that 3D Gain plot where it ranges from -9.2 to $3.6 \mathrm{~dB}$.

\section{CONCLUSION}

A self-diplexing antenna using SIW technique for C-Band applications has been successfully designed and simulated using HFSS. Two quarter-mode cavity resonators, placed orthogonally to every other, are used for radiation. The quarter mode resonators are acquired from half-mode SIW resonator by inserting a slanted one open-ended rectangular slot. Each quarter-mode resonator radiates independently, at the corresponding resonance without affecting other. The measured and simulated results show a depth agreement with one another. The obtained resonant frequencies are often used for C-Band applications.

\section{REFERENCES:}

[1] Liu Y, Chen S, Ren Y, Cheng J, Liu QH. A dual polarized microstrip antenna with L-shape backed cavity for X-band applications with a broadband proximity. AEU-International Journal of Telecommunications and Electronics. Sep 30, 2015; 69(9):1226-32

[2] Kumar A, Raghavan, S. The SIW Cavity-Backed Slot Antenna is self-diplexing. IEEE Antennae and Letters of Wireless Propagation. In 2018, vol. 17, (5) from:772-75.

[3] Park DK, Waterhouse R, Qian Y, Itoh T. Integrated antenna transceiver with self-diplexer for wireless use. International Symposium for the Society of Antennas and Propagation, 2001. IEEE 2001 (Vol. 3, pp. 444-447) Jul 8 IEEE.

[4] F. J. Herraiz-Martinez, E. Ugarte-Munoz, V. Gonzalez-Posadas, L. E. Garcia-Munoz and D.Segovia-Vargas, "Antennas focused on self-diplexer patches, "Trans-IEEE. Microwave. Theory tech., vol. 2009 57, section 5, pp. 1330-1340, May 2009

[5] Montero-de-paz J, Ugarte-Munoz E, V. Gonzalez-posdes V, Garcia Monuz and D. Multifrequency self-diplexed single path antennas loaded with split ring resonators. Progress in electromagnetic research 2011;113:47-66.

[6] Chang CC, Row JS. Dual -feed dual-polarization and high isolation. IEEE Transactions on antennas and propagation. 2009 Oct; 57(10):3405-9.

[7] Boyle KR, Undrik M, de Graauw A, Ligthart LP. A dual -fed, self -diplexing PIFA and RF front-end. IEEE transaction on antennas and propagation. $2007 \mathrm{Feb}$; 55(2):373-82.

[8] Lu YC, Lin YC. A mode-based method of developing dual-band and self-diplexing antennas using powered aperture double $\mathrm{T}$ stubes. IEEE Antennas and Propagation transactions. December 2012; 60(12):5596-603.

[9] Mukherjee S, Biswas A. Concept of integrated waveguide cavitybacked slot antenna with self-diplexing substrate. IEEE Antennae and Letters of Wireless Propagation. 2016; from 15:1775-8.

[10] Nandi S, Mohan A. A self-diplexing antenna assisted by the SIW Cavity. IEEE Antennae and Letters of Wireless Propagation. 2017; from 16:2708-11.

[11] Chaturvedi D, Raghavan S. Circular Quarter Mode SIW System antenna for WBAN. IETE-Research Journal. Aug 1:1-7, 2017.

[12] Deckmyn T, Agneessens S, Reniers AC, Smolders AB, Cauwe M, Ginste DV, Rogier H. A novel $60 \mathrm{GHz}$ wideband integrated waveguide antenna coupled with half-mode / quarter-mode substrates. IEEE Transactions and Propagation on Antennas. Oct 2017 